\title{
Homocystiene Profile in Elderly
}

Ola A. Hafiz ${ }^{1}$, Sarah A.Hamza ${ }^{1}$,Walaa W. Aly ${ }^{1}$,Wessam E.Saad ${ }^{2}$, Ahmed K.Mortagy ${ }^{1}$ Department of Geriatrics and Gerontology ${ }^{(1)}$, Department of Clinical Pathology ${ }^{(2)}$ Faculty of Medicine,Ain Shams University

\begin{abstract}
:
Background: Homocysteine (Hcy) is a sulfurated amino acid an elevated homocysteine level is a marker for a pathogenic process as well as a cause of pathology.

Method: it is across sectional study conducted on 91 elderly participants 60 years and older selected from geriatric outpatient clinic and geriatric inpatient departmentthey underwent comprehensive geriatric assessment, and homocysteine (Hcy) level in blood by Enzyme Immunoassay (EIA).
\end{abstract}

Results: homocysteine not significantly related to age, sex and functional status. Also mean Hcy level is $15.4 \mu \mathrm{mol} / \mathrm{liter}$.

Conclusion: further studies to evaluate Hcy level in elderly with different ages are recommended.

Keywords: Homocystiene, profile, elderly

\section{Introduction:}

Homocysteine (Hcy) is a sulfurated amino acid derived from ingested methionine found in cheeses, eggs, fish, meat, and poultry. It is directly toxic to neurons and blood vessels and can induce DNA strand breakage, oxidative stress, and apoptosis(1).

The methionine-homocysteine metabolic pathway intermediaries are $S$ adenosyl methionine and $S$ adenosylhomocysteine. The pathway produces methyl groups required for the synthesis of catecholamines and DNA. This is accomplished by remethylatinghomocysteine-using B12 and folate as cofactors-back to methionine (2).

Homocysteine is cleared by transulfuration to cysteine and glutathione, an important antioxidant. Transulfuration requires vitamins $\mathrm{B} 6$ and $\mathrm{B} 12$. The components of the homocysteinemethionine cycle are affected by genetic variation, diet, kidney and gastrointestinal diseases, and prescribed and over thecounter drugs. Since homocysteine is a sensitive indicator of $B$ vitamin deficiency, an elevated homocysteine level is a marker for a pathogenic process as well as a cause of pathology(2).

Elevated blood concentrations of the amino acid homocysteine are frequent in the elderly (3), especially as a consequence of nutritional deficiencies of vitamin B12 and folate (4).

Ueland and Refsum (5) noted impaired homocysteine metabolism seems to exist in $15-30 \%$ of patients with 
premature cardiovascular disease. Moderate hyperhomocysteinemia is a risk factor for cardiovascular disease, independent of conventional risk factors.

Results of a recent meta-analysis of prospective studies suggest that lowering the serum homocysteine level by $25 \%$ (about $3 \mu \mathrm{mol} /$ liter) decreases the risk for ischemic heart disease. Reduction of levels reduces the risk of heart disease by $11 \%$ and stroke by $19 \%(6)$.

Mild HHcy has been observed in type I diabetic patients with micro albuminuria and nephropathy and may explain the increased risk of vascular disease in this high-risk population (7).

\section{Subjects and Methods}

\section{A) Subjects:}

The study is a cross sectional study performed in geriatric clinics and geriatric inpatient ward in the department of geriatrics and gerontology, Ain Shams University Hospital. The study participants were 91 elderly (60 years and older)

Verbal consent was taken from all subjects before enrollment in the study. Subjects who refused to participate in the study, patients suffering from renal failure (creatinine clearance $<60 \mathrm{ml} / \mathrm{min}$ ) and those with drug or alcohol abuse were excluded from the study. Patients on drugs such as methotrexate, carbamazepine, phenytoin, were also excluded as these drugs can affect homocysteine metabolism and may give elevated levels of Hcy (8).
Assessment: All participants underwent comprehensive geriatric assessment which include: Full history, examination,Functional assessment by:Activities of daily living (ADL) (9) and Instrumental activities of daily living (IADL) (10).

All participants underwent measurement of serum homocysteine by Enzyme Immunoassay (EIA) by the following technique:

\section{1-Analytical Methods:}

\section{Sampling:}

Under complete aseptic condition, 3 milliliters of venous blood were collected by venipuncture from all patients and healthy controls in sterile plain tubes (sterile dry vacutainers). Samples were left to clot for 20 minutes, and then centrifuged at $1000 \mathrm{xg}$ for 10 minutes. Sera were separated stored at $-20^{\circ} \mathrm{C}$ until the assay of homocysteine level. Heamolysed samples were discarded, repeated thawing and freezing was avoided.Food consumption can affect circulating homocysteine levels as protein rich meals give higher homcysteine values, therefore should be avoided late in the day before sampling.

\section{Measurement of Hcy:}

Quantitative determination of total Lhomocysteine in human serum was carried out by Axis ${ }^{\circledR}$ Homocysteine Enzyme Immunoassay (EIA) (11).

Axis ${ }^{\circledR} \quad$ Homocysteine Enzyme Immunoassay (EIA) is an enzyme immunoassay specific for determination 
of L-form Hcy which is the only form present in the blood (12).

Protein-bound Hcy is reduced to free Hcyby use of dithiothreitol (DTT), and enzymatically converted to Sadenosyl-L-homocysteine (SAH)by the use of SAH hydrolase and excess adenosine (Ad) in a separate procedure prior to the immunoassay (11). The solidphase enzyme immunoassay is based on competition between SAH in the sample and immobilized SAH bound to the walls of the microtitre plate for binding sites on a monoclonal anti-SAH antibody. After removal of unbound anti-SAH antibody, a secondary rabbit anti-mouse antibody labelled with the enzyme horse radish peroxidase (HRP) is added. The peroxidase activity is measured spectrophotometrically at $450 \mathrm{~nm}$ after addition of substrate, and the absorbance is inversely related to the concentration of Hcy in the sample.
Aset of low, medium and high controls of homocysteine level provided by the kit was used.

\section{Statistical Analysis:}

The collected data was revised, coded, tabulated and introduced to a PC using Statistical package for Social Science (13). The following tests were done: Chi-Square test, One-Way ANOVA test, Person Correlations test. The probability of error at 0.05 was considered significant, while at $\leq 0.01$ highly significant.

\section{Results:}

The study was conducted on 91 elderly patients with age ranging from 60-98 years with mean age 69.1( \pm 8.3$)$. As regard homocysteine level was ranged from $4-50 \mu \mathrm{mol} / \mathrm{L}$ with mean 15.4 \pm 8.9 with no statistical significant correlation with age (table 1). Also in the current study $52.8 \%$ of the participants were female and $47.3 \%$ were males with no statistical significant difference with Hcy level (table 2). As regard the function the majority of the participants were independent in ADL and IADL (75.8\% and $64.8 \%$ respectively) (tables 3-4-5).

Table (1): Descriptive statistics of age and homocysteine and Correlation of age with homocysteine:

\begin{tabular}{|c|c|c|c|c|c|}
\hline \multicolumn{3}{|c|}{ Descriptive Statistics } & \multicolumn{3}{|c|}{ Correlations } \\
\hline & Range & Mean \pm SD & & & $\begin{array}{l}\text { homocystsine } \\
\text { level }\end{array}$ \\
\hline AGE & $60.0-98.0$ & $69.088 \pm 8.379$ & \multirow[b]{2}{*}{ AGE } & $\mathbf{r}$ & -0.086 \\
\hline $\begin{array}{c}\text { homocystsine } \\
\text { level }\end{array}$ & $4.0-\quad 50$ & $15.371 \pm 8.933$ & & $\begin{array}{l}\text { P- } \\
\text { value }\end{array}$ & 0.423 \\
\hline
\end{tabular}


Table (2): comparison of homocysteine level between males and females:

\begin{tabular}{|c|c|c|c|c|c|c|c|c|}
\hline & \multicolumn{6}{|c|}{ SEX } & \multirow{2}{*}{\multicolumn{2}{|c|}{ T-Test }} \\
\hline & \multicolumn{3}{|c|}{ Female } & \multicolumn{3}{|c|}{ Male } & & \\
\hline & Mean & \pm & SD & Mean & \pm & SD & $\mathbf{t}$ & P-value \\
\hline homocystsine level & 15.272 & \pm & 9.047 & 15.477 & \pm & 8.916 & -0.108 & 0.915 \\
\hline
\end{tabular}

Table (3): ADL and IADL of the participants:

\begin{tabular}{|c|c|c||c|c||}
\hline \multicolumn{2}{|c|}{ ADL } & \multicolumn{2}{c||}{ IADL } \\
\hline \hline & $\mathbf{N}$ & $\%$ & $\mathbf{N}$ & $\%$ \\
\hline Independent & 69 & 75.82 & 59 & 64.84 \\
\hline Assisted & 14 & 15.38 & 16 & 17.58 \\
\hline Dependent & 8 & 8.79 & 16 & 17.58 \\
\hline Total & 91 & 100.00 & 91 & 100.00 \\
\hline
\end{tabular}

Table (4): One way ANOVA test to compare between ADL and homocysteine level:

\begin{tabular}{|c|c||c|c|c|c|c||}
\hline \multicolumn{2}{|c||}{ Descriptives } & \multicolumn{3}{c||}{ ADL } & \multicolumn{2}{c|}{ ANOVA } \\
\cline { 3 - 6 } \multicolumn{2}{|c|}{} & Independent & assisted & dependent & F & P-value \\
\hline \multirow{2}{*}{$\begin{array}{c}\text { homocystsine } \\
\text { level }\end{array}$} & Mean & 15.119 & 16.107 & 16.188 & \multirow{2}{*}{0.105} & 0.900 \\
\cline { 2 - 5 } & SD & 8.746 & 5.923 & 14.643 & & \\
\hline
\end{tabular}

Table (5): One way ANOVA test to compare between IADL and homocysteine level:

\begin{tabular}{||c|c|c|c|c||c|c||}
\hline \multirow{2}{*}{ Descriptives } & \multicolumn{3}{|c||}{ IADL } & \multicolumn{2}{c||}{ ANOVA } \\
\cline { 3 - 7 } \multicolumn{2}{|c|}{} & Independent & assisted & dependent & F & P-value \\
\hline \hline \multirow{2}{*}{ homocystsine level } & Mean & 14.431 & 16.700 & 17.531 & \multirow{2}{*}{0.954} & 0.389 \\
\cline { 2 - 5 } & SD & 8.271 & 9.651 & 10.541 & & \\
\hline
\end{tabular}

\section{Discussion:}

In our study the age not significantly related to homocysteine which not agreed with many studies as Reif et al (14); El-Sammak et al. (15) which found that homocysteine were positively correlate with aging.

Also, plasma homocysteine level was measured in 159 healthy Turkish 
individuals. The data indicate the significance of age-associated differences of homocysteine levels (16).

Plasma Hcy concentrations were significantly higher in elderly than in young female subjects (17)

Plasma total homocysteine concentrations in the 385normal Chinese subjects showed that both normal females and males above the age of 50 years old exhibited significant increases of plasma homocysteine compared to subjects below this age (18).

This difference may be due to small range of age butit indicate that Hcy level although increase with age but the rate of increase not markedly observed.

Our study reports that mean homocysteine level was 15.4 (SD \pm 8.9$)$ which agreed with Macllroy et al. (19) and Kerkeni et al. (20) depressed groups but not control groups as Hcy is lower in control groups

In another comparative cross-sectional study of 47 depressed patients of Turkish descent and 28 of Dutch descent the mean of homocysteine was $11.2 \mu \mathrm{mol} / \mathrm{L}$ (SD6.30) in Turkish descent and $10.61 \mu \mathrm{mol} / \mathrm{L}(\mathrm{SD}$ $\pm 0.04)$ in those of Dutch descent (21).

These results were greater from other studies this may due to effect of comorbidities as the sample taken from geriatric patient.

In the current study, sex not significantly related to Hcy this disagreed with Chen et al. (22) who found that average plasma Hcy was $13.3+/-0.6$ micromol/ L for males and 10.6+/-0.7 micromol/L for females. Also homocysteine concentration was significantly greater in males than in females in studies done with Ardawi et al. (23) and Setnik et al. (24).

This may be due to that plasma total homocysteine (Hcy) levels are higher in men and postmenopausal women, but it is not known whether this difference is related to sex steroids.

In the current study there was no association between homocysteine and functional impairment, this disagreed with Kuo et al. (25) who stated that elevated homocysteine was associated with disability in ADL, IADL. Also high Hcy concentration can be associated with functional impairment (26)

Conclusion: further studies to evaluate Hcy level in elderly with different ages are recommended to evaluate the difference between elderly other age groups.

\section{References:}

1. Mattson MP and Shea TB (2003): Folate and homocysteine metabolism in neural plasticity and neurodegenerative disorders. Trends Neurosci., 26:137-46.

2. Coppen $A$ and Bolander-Gouaille $C$ (2005): Treatment of depression: time to consider folic acid and vitamin B12. J Psychopharmacol., 19:59-65.

3. Kuo HK, Sorond FA, Chen JH, Hashmi A, Milberg WP and Lipsitz LA (2005): The role of homocysteine in multisystem agerelated problems: a systematic review. J Gerontol A: Biol Sci Med Sci., 60 (2005):M1190-M1201.

4. Haan MN, Miller JW, AielloA, Whitmer RA, Jagust WJ, Mungas DM, Allen LH and Green R (2007): Homocysteine, vitamins B, and the incidence of dementia and cognitive impairment: results from the Sacramento Area Latino Study on Aging. Am J Clin Nutr., 85:511-7. 
5. Ueland PM and Refsum H (1989): Plasma homocysteine, a risk factor for premature vascular disease: plasma levels in healthy persons; during pathologic conditions and drug therapy (Norwegian). Nord Med., 104: 293-8.

6. Wolters $M$, Strohle $A$ and Hahn A (2004): Age-associated changes in the metabolism of vitamin B (12) and folic acid: prevalence, aetiopathogenesis and pathophysiological consequences (German). Z Gerontol Geriatr., 37:109-35.

7. Vaccaro O, Perna AF, Mancini FP, Iovine C, Cuomo V, Sacco M, et al (2000): Plasma homocysteine and microvascular complications in type 1 diabetes. Nutr Metab Cardiovasc Dis., 10:297-304.

8. Desouza C, Keebler M, McNamara DB and Fonseca V (2002): Drugs affecting homocysteine metabolism: impact on cardiovascular risk. Drugs, 62 (4):605-16.

9. Katz, S. (1963): Katz Index of Activities of Daily Living, Journal of the American Medical Association; 185:915.

10. Lawton, M.P. and Brody, E.M. (1969): Assessment of older people: self-maintaining and instrumental activities of daily living. Gerontologist; 9: 179-86.

11. Sundrehagen E (1997): Enzymatic assay for homocysteine and a kit therefore. Axis Biochemicals ASAEP623174/ US5631127.

12. Frantzen F, Faaren AL, Alfheim $I$ and Nordhei AK (1998): An enzyme conversion immunoassay for determining total homocysteine in plasma or serum. Clin Chem., 44:311-316.

13. SPSS 15.0.1 for windows; SPSS Inc, Chicago, IL, 2001.

14. Reif A, Schneider MF, Kamolz $S$ and Pfuhlmann B (2003): Homocysteinemia in psychiatric disorders: association with dementia and depression, but not schizophrenia in female patients. J Neural Transm., 110(12):1401-11.

15. El-Sammak M, Kandil M, El-Hifni S, Hosni R and Ragab M (2004): Elevated plasma homocysteine is positively associated with age independent of C677T mutation of the methylenetetrahydrofolate reductase gene in selected Egyptian subjects. Int J Med Sci., 1(3):181-92.

16. Taskin G, Yilmaz Sipahi E, Yildirimkaya M, Nadirler F, Halloran M, Ayoglu FN and Laleli Y (2006): Plasma total homocysteine levels in a healthy Turkish population sample. Acta Cardiol; 61(1):35-42.

17. Strassburg A, Krems C, Lührmann PM, Hartmann $B$ and Neuhäuser-Berthold $M$
(2004): Effect of age on plasma homocysteine concentrations in young and elderly subjects considering serum vitamin concentrations and different lifestyle factors Int J Vitam Nutr Res., 74(2):129-36.

18. Chou ST, Ko LE, Lim PS, Huang JL and Yang CS (2000): Effect of age and sex on plasma total homocysteine in Taiwanese subjects. Chin J Physiol., 31; 43(4):159-64.

19. Macllroy SP, Dynan, K.B., Lawson, J.T., Patterson, C.C. and Passmore, AP. (2002): Moderately elevated plasma homocysteine, methylenetetrahydrofolate reductase genotype, and risk for stroke, vascular dementia, and Alzheimer disease in Northern Ireland. Stroke, 33: 2351-6.

20. Kerkeni M, Addad F, Chauffert M, Myara A, Gerhardt M, Chevenne D, Trivin F, Farhat MB, Miled A and Maaroufi K (2006): Hyperhomocysteinaemia, methylenetetrahydrofolate reductase polymorphism and risk of coronary artery disease. Ann. Clin.Biochem., 43(Pt 3): 200-6.

21. Güzelcan $Y$ and van Loon $P$ (2009): Vitamin B12 status in patients of Turkish and Dutch descent with depression: a comparative cross-sectional study.Ann Gen Psychiatry, 8:18.

22. Chen KJ, Pan WH, Yang FL, Wei IL, Shaw NS and Lin, B.F. (2005): Association of B vitamins status and homocysteine levels in elderly Taiwanese.Asia Pac J ClinNutr., 14(3):250-5.

23. Ardawi MS, Rouzi AA, Qari MH, Dahlawi FM and Al-Raddadi RM (2002): Influence of age, sex, folate and vitamin B12 status on plasma homocysteine in Saudis. Saudi Med J., 23(8):959-68.

24. Setnik B, de Souza FG, d'AlmeidaV and Nobrega JN (2004): Increased homocysteine levels associated with sex and stress in the learned helplessness model of depression. Pharmacol Biochem Behav., 77(1):155-61.

25. Kuo, HK, Liao KC, Leveille SG, Bean JF, Yen CJ, Chen JH, Yu YH and Tai TY (2007): Relationship of homocysteine levels to quadriceps strength, gait speed, and late-life disability in older adults. J Gerontol A BiolSci Med Sci; 62(4):434-9.

26.Marengoni A, Cossi S, De Martinis M, Calabrese PA, Orini S and Grassi V (2004): Homocysteine and disability in hospitalized geriatric patients. Metabolism, 53(8):1016-20. 